\title{
Training hydrologists to be ecohydrologists: a "how-you-can-do-it" example leveraging an active learning environment for studying plant-water interaction
}

\author{
S. W. Lyon ${ }^{1,2}$, M. T. Walter ${ }^{3}$, E. J. Jantze ${ }^{1}$, and J. A. Archibald ${ }^{3}$ \\ ${ }^{1}$ Physical Geography and Quaternary Geology, Stockholm University, Stockholm, Sweden \\ ${ }^{2}$ Navarino Environmental Observatory (NEO), Messinia, Greece \\ ${ }^{3}$ Biological and Environmental Engineering, Cornell University, New York, USA
}

Correspondence to: S. W. Lyon (steve.lyon@natgeo.su.se)

Received: 11 July 2012 - Published in Hydrol. Earth Syst. Sci. Discuss.: 9 August 2012 Revised: 7 January 2013 - Accepted: 7 January 2013 - Published: 22 January 2013

\begin{abstract}
Structuring an education strategy capable of addressing the various spheres of ecohydrology is difficult due to the inter-disciplinary and cross-disciplinary nature and general breadth of this emergent field. Clearly, there is a need for such strategies to accommodate more progressive educational concepts while highlighting a skills-based education. To demonstrate a possible way to develop courses that include such concepts, we offer a case-study or a potential "how-you-can-do-it" example from a recent course set in an ecohydrological context co-taught by teachers from Stockholm University and Cornell University at Stockholm University's Navarino Environmental Observatory (NEO) in Costa Navarino, Greece. This course focused on introducing hydrology Master's students to some of the central concepts of ecohydrology, while at the same time supplying processbased understanding relevant for characterizing evapotranspiration. As such, the main goal of the course was to explore some of the central theories in ecohydrology and their connection to plant-water interactions and the water cycle in a semiarid environment. While this course is still in its infancy with regards to addressing some of the more in-depth aspects of ecohydrology, it does provide a relevant basis with an initial emphasis on the more physical concepts of ecohydrology from which to build towards the more physiological concepts (e.g., unique plant adaptations to water availability or differences in water use between native plants and irrigated vegetation). In addition to presenting this roadmap for ecohydrology course development, we explore the utility and effectiveness of adopting active teaching and learning strate-
\end{abstract}

gies drawing from the suite of learn-by-doing, hands-on, and inquiry-based techniques in such a course. We test a potential gradient of "activeness" across a sequence of three teaching and learning activities. Our results indicate that there was a clear advantage for utilizing active learning with a preference among the students towards the more "active" techniques. This demonstrates the added value of incorporating even the simplest active learning approaches in our ecohydrology (or general) teaching.

\section{Introduction}

Ecohydrology is an evolving discipline that deals with the interaction between ecosystems and hydrology. The field of ecohydrology has been rapidly growing since early work on vegetation and hydrology interactions (e.g. Hack and Goodlett, 1960; Penman, 1963; Eagleson, 1978). Today, ecohydrology still maintains an active and healthy discussion about what forms the core of this emergent field (e.g., Hannah et al., 2004; Wilcox, 2010) and where the future will be found (e.g., King and Caylor, 2011). This rapid growth and discussion on the research side has been mirrored more recently in the associated education. Take, for example, the work by McClain et al. (2012) outlining a potential structure for ecohydrology education. They clearly identify the potential pitfalls and complex challenges associated with teaching and education within ecohydrology stemming from the various disciplines involved. With that, McClain et al. (2012) 
propose an "educational vision focused on the development of professional and personal competencies to impart a depth of scientific knowledge in the theory and practice of ecohydrology and a breadth of cross-cutting knowledge and skills to enable ecohydrologists to effectively collaborate with associated scientists and communicate results to resource managers, policy-makers, and other stakeholders" necessitated by the trans-disciplinary nature of ecohydrology.

According to McClain et al. (2012), this creates various "spheres" of ecohydrology that should be addressed in order to train the future generation of ecohydrologist such that they can play a leading role in environmental problem solving. As outlined in McClain et al. (2012) in this special issue on "Hydrology education in a changing world", these principle spheres consider (i) climate-soil-vegetationgroundwater interactions at the land surface; (ii) riparian runoff, flooding, and flow regime dynamics in river corridors; and (iii) fluvial and groundwater inputs to lakes/reservoirs, estuaries, and coastal zones. Each conceptual sphere (and their interface - see McClain et al., 2012) can bring about its own unique set of challenges that reflect the broad range of topics under the umbrella of ecohydrology. For example, the required flow regime and subsequent dynamics necessary to protect desired ecological functions represent a key focal area of active ecohydrological research (Arthington et al., 2010). Further, much work currently centers on how the composition and configuration of vegetation alter the hydrological cycle across scales in connection with process-level changes due to land use alteration (e.g., van Griensven et al., 2006; Wilcox, 2010). While the research field of ecohydrology abounds with challenges and numerous avenues for potential advancements, the issue still remains how to best address these different "spheres" in practice and, more specifically, in our courses.

This issue is compounded by the inter-disciplinary and cross-disciplinary nature of ecohydrology, which can become a challenge in the classroom. Such challenges are longstanding in standard hydrology education due to its inherent interdisciplinary nature (Wagener et al., 2007) and can lead to combinations of intended learning outcomes (ILOs) in courses that may not be easily or completely achieved using traditional lecture-based learning environments or using basic problem-solving techniques (Lyon and Teutschbein, 2011). As such, ecohydrology education may be better achieved through inclusion of more learner-centered approaches and strategies (e.g. experiential learning, inquirybased learning, and collaborative learning) (Huba and Freed, 2000). These approaches are traditionally considered to fall under the broad umbrella of active learning approaches (Bonwell and Eison, 1991).

Active learning is defined in a general sense as any instructional method that engages students in the learning process (Prince, 2004). As such, active learning requires students to carry out meaningful learning activities and think about what they are doing (and why they are doing it) (Bon- well and Eison, 1991). Such approaches lend themselves organically to natural science disciplines. For example, geography education has seen benefits from more active learning approaches since it has traditionally contained collaborative, hands-on, and experiential learning through lab and field-based learn-by-doing courses (Spronken-Smith, 2005; Levia and Quiring, 2008). In hydrology education, Lyon and Teutschbein (2011) demonstrated how students both preferred and performed better in a problem-based learning environment, which is, by definition, an active learning environment in nature. Shaw and Walter (2012) point to the potential for inquiry-based comparative analysis approaches centered on resolving similarities and differences between hydroclimatic regions to help in linking across disciplines and developing critical thinking within hydrology courses. Given the history of success adopting active-learning approaches in natural sciences and hydrology, it stands to reason that ecohydrology education could also benefit from adopting such approaches. What is yet to be seen is to what extent ecohydrology courses (and all our courses in general) need to be "active" in nature to achieve their goals.

Taken all together, there is clear need for ways forward in ecohydrology education that can include/promote active learning environments. McClain et al. (2012) highlight an educational framework for training hydrologists to be ecohydrologists. Here, we seek to begin adding details to such a framework in the form of suggesting potential course structures. Specifically, we present a potential "how-you-can-doit" example from a recently conducted course set within the context of ecohydrology. From this starting point, we consider a potential roadmap forward on how to design courses that promote an active learning environment while being targeted at ecohydrology. Further, we test the utility of such an active learning environment (from both the students' and teachers' perspectives) for achieving the course goals (which are likely representative of what would be expected from many ecohydrology courses). We also seek to answer the question "How active is active enough?" when considering how to design and structure teaching and learning activities (TLAs) in such a course.

\section{Ecohydrology: a Mediterranean perspective}

Recently, an international Master's course was developed by Steve W. Lyon, Department of Physical Geography and Quaternary Geology, Stockholm University (Sweden) and M. Todd Walter, Department of Biological and Environmental Engineering, Cornell University (USA) for the Navarino Environmental Observatory (NEO). The goal of this course was to supplement general hydrological education available to students by exploring some of the central concepts of ecohydrology. This course, entitled Ecohydrology: A Mediterranean perspective brought together students from both universities to investigate processes driving plant-water 
interactions in the Mediterranean environment surrounding Costa Navarino where the NEO is located. Students designed and carried out a field experiment highlighting both the location's uniqueness and potential sensitivity to climatic changes that emphasized the more physical side of ecohydrology. This provided an excellent opportunity for both the students and teachers to bridge the gap between theory and practice (McClain et al., 2012) by beginning to place the NEO in an ecohydrologic-relevant framework.

In this initial offering, the course was designed primarily to supplement the existing Hydrology, Hydrogeology, and Water Resources Master's Program within the Department of Physical Geography and Quaternary Geology at Stockholm University by offering a topic-specific elective. With that, the explicit design of this course may differ from those conceptualized or envisioned in McClain et al. (2012) as it seeks to fit the intended learning outcomes of a more hydrology-focused Master's program. The Hydrology, Hydrogeology, and Water Resources Master's Program seeks to provide broad knowledge in the field of hydrology and water resources with substantially deeper knowledge and insight into current research and development activities. Further, and in a more general sense, the program encourages students to critically, independently and creatively identify and formulate water issues and to plan and carry out advanced tasks within specified time limits, so to contribute to the development of knowledge around these issues.

The main goal and intended learning outcomes (ILOs) of the course (Table 1) were, thus, designed to explicitly target some of the central concepts of ecohydrology while building on the hydrological education background of the students. Due to the broad and varied concepts in ecohydrology (d'Odorico et al., 2010; Wilcox, 2010), the relative "newness" of the course in its first-time offering, and natural settings of the NEO, the course attempted to narrow in on plantwater interactions and coupled land-water management impacts on evapotranspiration. We have uploaded the course syllabus as supplementary information to provide a complete overview of the course (including assessment methods and grading criterion). The course was structured to correspond to about 3-4 weeks of teaching time and to be carried out during a summer term following the first sequence of Master's level hydrology education. In the following, we provide a general overview of the course's three main teaching and learning activities (TLAs) (Biggs and Tang, 2007) and the motivation behind them.

\subsection{Teaching and Learning Activity (TLA) \#1: what is ecohydrology?}

In this first TLA of the course, students reviewed central concepts of ecohydrology through a combination of stateof-the-science literature review and discussion (see reading list in syllabus as supplementary information). The goal here was to build the students' knowledge base around the ques-
Table 1. The main goal and intended learning outcomes (ILOs) for the recently taught course Ecohydrology: A Mediterranean perspective.

\begin{tabular}{|c|c|}
\hline Main Goal & $\begin{array}{l}\text { The main goal of the course was to explore } \\
\text { central theories in ecohydrology and their } \\
\text { connection to plant-water interactions and the } \\
\text { water cycle in a semiarid environment. }\end{array}$ \\
\hline ILO \#1 & $\begin{array}{l}\text { Explain and differentiate the basic theories and } \\
\text { current literature that forms the core } \\
\text { of ecohydrology. }\end{array}$ \\
\hline ILO \#2 & $\begin{array}{l}\text { Synthesize relevant data and observations to } \\
\text { provide an ecohydrological framework to } \\
\text { characterize a region and set up a hydrologic } \\
\text { model. }\end{array}$ \\
\hline ILO \#3 & $\begin{array}{l}\text { Define, develop, and conduct field-based } \\
\text { research experiments to test fundamental } \\
\text { assumptions behind our state-of-the-science } \\
\text { understanding of the interactions between the } \\
\text { water cycle and vegetation. }\end{array}$ \\
\hline ILO \#4 & $\begin{array}{l}\text { Communicate via written scientific reports and } \\
\text { presentations how the previous three } \\
\text { outcomes intersect for Mediterranean } \\
\text { perspective using the Navarino Environmental } \\
\text { Observatory (NEO) as an example. }\end{array}$ \\
\hline
\end{tabular}

tion "What is ecohydrology?". This first step was necessary in this specific case study example as the general composition of students in the course (i.e., upper level Master's students following a program in Hydrology, Hydrogeology and Water Resources) were unfamiliar with the main tenants of ecohydrology.

Learning in this TLA was designed to be exploratory and self-regulated in nature. Students were presented with a subset of the state-of-the-science literature relevant for ecohydrology and asked to summarize and synthesize across the seemingly divergent topics. These topics focused on ecohydrology in a general sense, evapotranspiration mechanisms and processes, and hydroclimatic assessments in Greece and the Mediterranean region to provide a site-specific background relevant for this course. Students were encouraged (and required) to explore the current literature on these topics and include their own references (i.e., those not specified by the instructors) as they attempted to answer the central question of this TLA. After approximately one week, students lead discussions on the breadth and interconnections across the literature provided and the literature they gathered. In addition to leading discussion sessions, students were required to complete a short, written summary that could be assessed by the teachers (Table 2). Based on these summaries and the in-class discussion, students were able to identify several central concepts with regards to climate-soil-vegetationgroundwater interactions at the land surface. Student perspectives were clearly guided by the initial assigned literature list and course structure (see the Supplement). The assigned 
Table 2. Selected central concepts of ecohydrology identified by students with regards to ILO \#1 in the course Ecohydrology: A Mediterranean perspective.

ILO \#1: What is ecohydrology?

Ecohydrology studies how ecosystems and hydrology mutually affect and feedback on each other.

Ecohydrology investigates interrelationships between biota and water, raising questions about potential human impacts on water resources.

Spatiotemporal climate-soil-vegetation dynamics appear central to much ecohydrology research and many key concepts. In the field of ecohydrology, different approaches (i.e., from the viewpoint of an ecologist or a hydrologist) can lead to different end results and interpretations.

Ecohydrology can be considered as a way to look deeper into the importance of the boundaries and integration between hydrology and landscape perspectives.

Ecohydrology is a field that should operate in a

cross-disciplinary mode in order to transcend both ecology and hydrology.

literature could, of course, be shifted in future course offerings to highlight or encompass different aspects of the field (i.e., plant water use, variations among species, variations among crops and "wild" plants, etc.). Ultimately, the freeform discussions in this TLA allowed for identification of knowledge gaps to be better addressed in the next two TLAs in the course.

\subsection{Teaching and Learning Activity (TLA) \#2: calculations of evapotranspiration}

This second main TLA specifically targeted providing relevant "tools" for the students' toolboxes such that they could tackle designing and carrying out an ecohydrologicalrelevant experiment. Here, we specifically refer to the appropriate theories and methodologies to characterize evaporative fluxes from the landscape. This is in line with the skills-based style of education called for by McClain et al. (2012). In this TLA, students developed relevant hydrologic models (with teacher guidance) to estimate evaporative fluxes using a myriad of approaches. Specifically, we targeted using a water balance (closure) approach, several empirical temperaturebased approaches, and traditional energy balance relationships for estimation of potential and actual evapotranspiration relevant for the hydroclimatic setting of NEO. The modeling allowed for investigation of the interaction between plants and water from a mechanistic perspective to exemplify the terrestrial fluxes of water from the landscape. Modeling was carried out in an open computer lab setting with the students encouraged to interact and help each other. The attempt here was to motivate cooperative learning. In addition, the in-class discussions also provided ample, often spontaneous, teaching moments to address knowledge gaps that were inevitable given the short timeframe the students had to synthesize the concept(s) of ecohydrology and experiment with different modeling approaches. These teaching moments included, for example, comparison of potential versus actual evapotranspiration conceptualizations, discussion of plant transpiration/water uptake responses under drought conditions, and basic review of the differences between empirical and physics-based modeling approaches. As such, these teaching moments were used somewhat to help guide the learning process in general.

This TLA leveraged off existing hydroclimatic monitoring collected in connection with ongoing NEO field activities. Students were given about 3-yr of 15-min raw data covering temperature, precipitation, and streamflow. They needed to perform quality controls on these raw data and reduce them to daily information. It should be noted that while working with raw data is often a good first step for students, it can be a time sink in many situations depending on student abilities. For this course, teachers were comfortable with the students' existing skills at working with raw data through previous experiences and design of the prerequisites of the course. After compiling the data, students were asked to develop a simple water balance (which scaffolds on their previous hydrology courses) and implement temperature-based empirical estimates of potential and actual evapotranspiration (e.g., Langbein, 1949; Turc, 1954; Hargreaves and Samani, 1982). Lastly, students developed a full Penman-Monteith (Penman, 1948; Monteith, 1981) estimate of potential evaporation for the NEO site. Rather than teaching this explicitly, students were directed to existing publically available and standard techniques (e.g., Allen et al., 1998) to explore the range of approaches and carry out the calculations. This allowed students the opportunity to trouble shoot and make the necessary approximations and assumptions required when faced with data limitations.

By adopting several different approaches, students were able to appreciate a full spectrum of possible estimates for potential evapotranspiration. Student-estimated potential evapotranspiration values spanned the range from about $900 \mathrm{~mm}$ per year using the Thornthwaite approach (Thornthwaite and Holzman, 1939) to about $1300 \mathrm{~mm}$ per year using the Penman-Monteith approach. These various estimates allowed teachers to highlight the implications and potential limitations associated with the various parameterizations in each approach, the assumptions made when synthesizing across various hydroclimatic datasets, and the potential added value of site-specific estimation. It also allowed for students to explore the potential variability within one given approach (e.g., the full Penman-Monteith method) depending on the values taken for the numerous physical and parameterized relationships in the equation. 


\subsection{Teaching and Learning Activity (TLA) \#3: designing and conducting an ecohydrological experiment}

This third TLA was carried out in the field at the NEO in southwestern Messina region of Greece. Students were tasked with designing a field experiment to test key assumptions and simplifications relevant to the calculations carriedout in TLA \#2 and connect these estimates back to ecohydrological concepts outlined in TLA \#1. These include, for example, the selection of a representative value for relative humidity when estimating evapotranspiration given the inherent heterogeneity faced at the landscape scale and the potential impact of diurnal variations on net radiation considered in energy balance estimates. Setting the structure and nature of this experiment was fully in the hands of the students. As such, students were required to self-organize and divide tasks accordingly to design and complete their experiment. This fostered a collaborative learning environment. Teachers provided some general overview and detailed knowledge when necessary (e.g., detailed lectures on Penman-Monteith calculations or demonstrations of how to use field equipment).

During the visit to the NEO (about 5 days in total), students took time to brainstorm ideas for relevant experiments that took advantage of the location's unique features, the available equipment, and their own knowledge base. As background, NEO's uniqueness can be seen by its geographic location in a warm Mediterranean landscape offering an abundance of energy to drive processes while at the same time experiencing seasonal water limitations. Further, the region's long-standing development of agriculture (mainly olives and some citrus) and more recent development of tourism offer strong gradients of land-water management for studying various aspects of ecohydrology. After an initial break-out style discussion to facilitate the brainstorming, teachers and student convened to synthesize and generate an overarching testable hypothesis with several supporting questions to be answered (Table 3). For the course offering considered in this case study, students centered their experiment around the more physical aspects of ecohydrology and put forward the hypothesis that evapotranspiration would be higher from more-managed locations (i.e., more extensively irrigated) and open water bodies than from less-managed locations (i.e., drip-irrigated and non-irrigated landscapes). To test this hypothesis and answer the supporting research questions, students conducted field measurements to gather data and performed the necessary calculations (Fig. 1). This TLA concluded with student presentations and discussion of the answers to their research questions, the validity of their hypothesis, and potential implications for regional development. This allowed students to collaborate and begin to place the NEO in an ecohydrology-relevant framework.

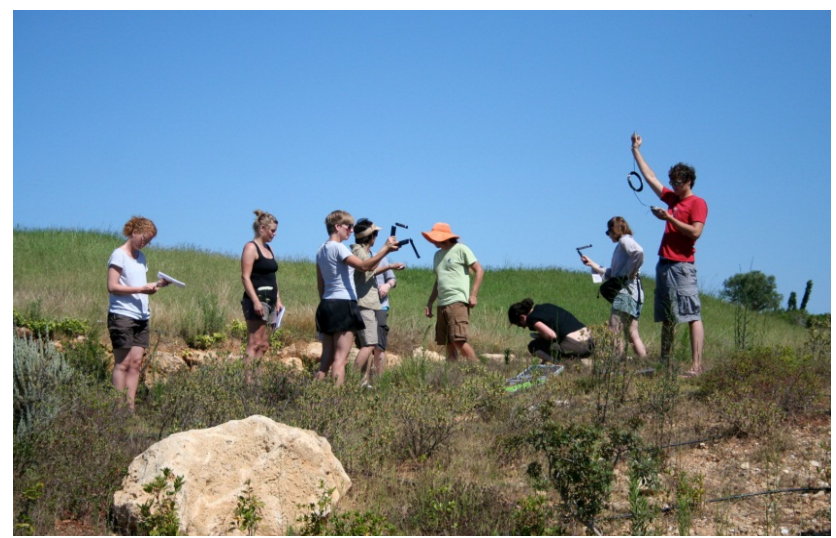

Fig. 1. Students in the field conducting measurements as part of their self-designed experiment in the course Ecohydrology: A Mediterranean perspective. M. Todd Walter (center with hat) supervises.

\section{Assessment of educational effectiveness: methods}

With regards to the aforementioned course structure and TLAs, the intention was to explicitly involve a gradient of active learning strategies. Again, active learning is defined in a general sense as any instructional method that engages students in the learning process (Prince, 2004). As such, these TLAs can be relatively ranked in the following broad sense according to their level of "activeness" and the degree to which student-student collaboration (e.g., from individuals to teams) was fostered. TLA \#1 offers a relative lowlevel of active learning as students self-guide their reading of state-of-the-science literature and self-regulate their intake of knowledge. TLA \#2 can be conceived as a mid-level of active learning environment as students work with processing raw data and applying/adapting relevant evapotranspiration equations. Further, by having open computer lab sessions where students are encouraged to assist each other, TLA \#2 brings in some aspects of cooperative learning. Lastly, TLA \#3 clearly has a high level of active learning as students design and carry out a field-based experiment. As the students self-organized into a functioning research team to complete the experiment, there was also high level of collaborative learning.

This potential gradient of active learning and studentstudent collaboration across the TLAs allowed us to gauge the effectiveness of a more versus less active learning environment spanning theoretical to practical application in an ecohydrology course. Here this was done by assessing students' views of the usefulness of the individual TLAs for achieving the overall goal of the course (Table 1). It should be noted that this provides a subjective point of view from the students' perspective that might not be equivalent to TLA effectiveness. We also asked the students if the course achieved its overall goal and if they felt the general active 
Table 3. The overarching hypothesis and several supporting questions developed and answered by students in the course Ecohydrology: A Mediterranean perspective.

\begin{tabular}{l}
\hline Overarching Hypothesis \\
\hline Evapotranspiration from the more-managed sites (and open \\
water site) are higher than the evapotranspiration from the \\
less-managed sites. \\
\hline Supporting Questions \\
\hline Is the surface/air temperature of the managed (irrigated) areas \\
lower than the unmanaged areas? \\
Is the relative humidity over the managed areas higher than over \\
the unmanaged areas? \\
Is the vapor pressure over the managed areas higher than over \\
the unmanaged areas? \\
What varies more over the course of the day: relative humidity \\
or vapor pressure? \\
Is the soil moisture higher in the managed areas than in the \\
unmanaged areas? \\
Is outgoing radiation (or albedo) higher from managed or \\
unmanaged areas? \\
How are the characteristics of the drip-irrigated (intermediately \\
managed) areas different from the sprinkler (highly managed) \\
and non-irrigated (unmanaged) areas? \\
How will pan evaporation differ between the open water site \\
(located in a fountain) and dry site (located in a parking lot)? \\
\hline
\end{tabular}

learning environment was effective for achieving this goal. This assessment was conducted using anonymous course evaluations at the end of the most recent course offering (June 2012). During this initial offering, we had an enrollment of 6 Master's level students all of which had completed the first year of the Hydrology, Hydrogeology and Water Resources Master's Program offered through the Department of Physical Geography and Quaternary Geology at Stockholm University. This background education was a prerequisite and created a more or less homogeneous prior Master's level educational background that could be considered to typify non-engineering hydrology students most teachers could experience in an ecohydrology course. The demographic distribution of the students was skewed towards female (5 of 6) in this cohort. Further, the mix of backgrounds (with regards to culture and undergraduate education) was fairly diverse with students coming from (and having been previously educated in) Sweden, Denmark, France, Germany, and Iran. The instructors came from Sweden and the US such that this cohort of students might represent the demographic distribution of classrooms at many universities.

Within the context of the written voluntary course evaluations completed at the end of the course, students were asked to quantify the utility of each TLA and the utility of the overall active learning environment on an integer scale from 1 (not very useful) to 5 (very useful). We avoided asking specifically about the ILOs as these were more custom tai- lored and aligned in relation to the TLAs (i.e., we would not expect TLA \#3 to help in achieving ILO \#1). In addition to quantifying student opinions on the utility of each TLA, we also collected student reflections via open-form comments on the usefulness of the TLAs and the overall active learning environment. Since the small course size and use of student reflections may tend to skew results, we have also elected to include some teacher reflections on the effectiveness of employing an active learning environment relative to more traditional forms of education. Also, we reflect on several alternative considerations that would help develop this course towards a more ecohydrology-relevant context. As these were gained through this initial offering, we hope this serves as a potential road map forward for incorporating active learning environments in ecohydrology education.

It should be noted that, in this methodology, we have not explicitly involved semi-structured qualitative interview techniques (or similar) that can be used to create a dialogue between students and teachers and may be useful when dealing with small sample sizes (such as those presented in this course). This limits to some extent our ability to isolate the effect of increasing active learning techniques across the three TLAs relative to other potentially confounding influences (e.g. personal preferences or dislikes of the different learning approaches used in the TLAs). While this is a shortcoming of our methodology, it serves as an opportunity for us to highlight the value of designing course evaluations in concert with educational researchers or pedagogical experts (when possible). Such consideration could, for example, better inform teachers about specific aspects of their courses such as the general utility of various techniques considered in the classroom.

\section{Results and discussion}

\subsection{On the general use of an active learning environment to achieve the course goal}

When asked if the course had achieved its main goal, $100 \%$ (6 out of 6) students responded that it had. We considered this as an indication of a successful course. In addition, this (from our perspective) lends credence to the following results and discussions in light of the small sample size considered and methodology used. When explicitly asked about the effectiveness of an active learning environment relative to their experiences with traditional lecture-based environments for achieving course goals, students by and large agreed that this active learning environment was useful (to very useful) in achieving course goals (Fig. 2). Considering the 1 to 5 integer scale as a scoring system, the average score was 4.67 across all students with regards to the effectiveness of the active learning environment. From this simple survey, the students were clearly aware of the attempt to involve an active learning environment and also that this approach differed 
from what they had previously experienced in some of the more traditional lecture-based environments offered across their hydrology Master's program of study. Again, this result helps lend support to the following comparisons with regards to the individual TLAs and their utility in such a course.

\subsection{How active is active enough?}

Clearly, there was agreement among the students that the more "active" the TLA with increased student-student collaboration, the more useful it was in achieving the course goal (Fig. 2). Again, considering the 1 to 5 integer scale as a scoring system, the average score for TLA \#1 for achieving the course goal was 3.33 while it was 4.17 for TLA \#2 and 4.50 for TLA \#3. To some extent, this result would be anticipated based on previous active-learning research in the sciences (e.g., Knight, 2004; Neilsen et al., 2012) and in hydrology (e.g., Lyon and Teutschbein, 2011). As such, it is not that surprising here that TLA \#3, where students designed and carried out an experiment, would be considered the most useful to achieve the course goal.

What might be interesting here, however, is that we see clear preference across what could be considered as a gradient of active learning strategies towards the more active approaches with increased student-student collaboration. This preference potentially demonstrates the added value we can assign in part to the effort of including additional active learning in teaching. Further, it highlights that even partial inclusion of active learning techniques have clear benefits. For example, moving from student exploration of literature (TLA \#1) to active participation in data analysis and calculations (TLA \#2) increased (significant at $p<0.05$ ) the utility of the TLAs (and thus efficiency of our teaching) in this course. This important result demonstrates that while it might not always be an option to immerse students in a full-on active learning environment, such as that fostered by TLA \#3 in this case study, there are alternative or incremental degrees of "activeness" that can add value to our courses. The potential for confounding influences do exist, however, as students could be simply responding to better TLA design across the three TLAs or to the classic time effect whereby cohorts of students become more comfortable with material and each other over time within a course. Still, the general trend seen across a clear gradient of TLA archetypes is encouraging for those faced with developing new course in emergent research fields (such as ecohydrology) where the funding or field sites may not yet be well established.

It is often problematic to measure what "works" in the classroom (Prince, 2004) and it should be noted that active learning environments and/or techniques may not always be optimal. For example, it is rather straightforward to see the benefits of a hands-on environment with regards to learning how to design and conduct experiments (e.g., SpronkenSmith, 2005; Levia and Quiring, 2008). Research has shown how active environments can increase course effectiveness

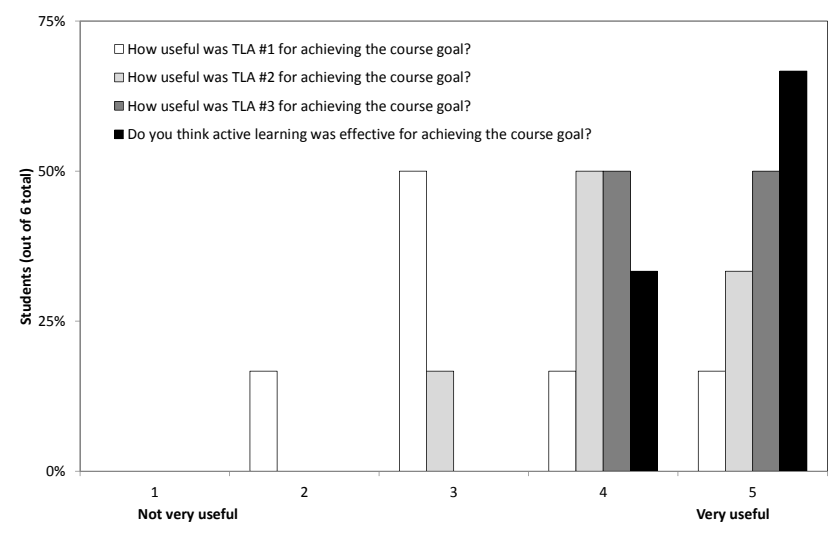

Fig. 2. Students' views regarding the utility of the active learning and various teaching and learning activities (TLAs) included in the course Ecohydrology: A Mediterranean perspective.

(e.g., Hake, 1998) with some evidence suggesting that even the simplest active techniques can improve student retention (e.g., student-student collaboration during lecture pauses as in Berry, 1991). Still, Mayer (2004) suggests that the "activity" in and of itself does not necessarily support learning indicating that active learning must involve well-designed activities that promote thoughtful engagement around learning outcomes in order to be effective. For example, some purely active techniques like discovery learning (where students engage with materials without any instructor support) have been shown to be inferior to guided learning with regards to gaining knowledge (Kirschner et al., 2006; Mayer, 2004). Also, as highlighted by Drake (2012), in many cases where active learning shows improved student retention of class materials, instructors still provided a lecture and guided (to some extent) the activities. The take-home message here is that an active learning environment needs to be thought out and planned for to be valuable. This is echoed in the following sections where student and teacher reflections on the course are presented.

\subsection{Student reflections}

Students clearly appreciate the feeling of being involved and engaged with their education, which was fostered in the active learning environment across this course. According to one student, it was "great to be involved from the start and get acquainted to a "scientific approach" of experimentation". Such engagement tends to promote deeper learning approaches (Biggs and Tang, 2007). The students were aware of and confirmed that deeper learning was taking place in this ecohydrology course. One student explicitly commented on TLA \#2 and TLA \#3 saying that together these TLAs helped put things in a practical context and "that made it much easier to understand". This contextual understanding is precisely the focal point called for by McClain et al. (2012) and can be 
seen as necessary for generating the next generation of functioning ecohydrologists.

Of course, as expected, there were criticisms with regard to the level of active learning involved in the course since this deviates from the traditional styles normally encountered by students. According to one student, "The structure felt somewhat unclear [during TLA \#1] and there was a bit too much confusion". This comment is likely motivated by the exploratory nature of the literature review used in TLA \#1. Another student agreed and felt that more lecture-based teaching would be useful in the early stages (during TLA \#1 and TLA \#2). This highlights the potential influence of poor TLA design on the results of this study with regards to assessing the impact of an increased active learning gradient across the three TLAs. These comments, further, touch on what can be a major roadblock for adopting more active learning approaches in our classrooms. Namely, this is the perceived difficulty by many teachers associated with incorporating active learning into courses. Such approaches can be perceived by students as, for example, unstructured relative to their lecture-based counterparts and may lead to low scores on course evaluations. This makes many teachers question if including active learning approaches are really worth the effort. Pathirana et al. (2012) note that "Innovative [active] teaching is not synonymous with providing the students a comfort zone in education. Indeed, students may feel somewhat uncomfortable, at least in the beginning, of the novel and unfamiliar approaches to education".

In our case study course, a student summed up this unstructured perception quite nicely by stating that in "[TLA \#1] we need more planned working [since] I prefer more planned working to know what I should do next". It is likely that the student identified the safety associated with planned lectures and uncertainty associated with open-ended questions (Lyon and Teutschbein, 2011) and experimentation. Still, it can be argued that it is exactly the creative thinking needed to solve such problems that we would like our students to obtain in an ecohydrology course (McClain et al., 2012) or in a science-based Master's program in general. This seems to justify the potential added effort associated with developing and incorporating active learning methods in our teaching.

Although these student reflections are good indications that active teaching styles like those developed for this course are effective, we recognize that student feedback is not always the best indicator of this as they are subjective assessments. Pathirana et al. (2012) caution that although "student evaluations provide useful signals about such situations and can be invaluable mechanisms of feedback on how students feel [...] they do not necessarily provide good indications on how effective the education is". Recognizing this potential shortcoming, we would recommend utilizing additional techniques to gather and assess student feedback. This could involve, for example, inviting a neutral party (such as an educational researcher) to conduct more detailed student in- terviews. Without this level of detail, we concede that it is difficult to isolate the active learning impact on student experiences as there are many potential confounding aspects (e.g., improved TLA design across the three activities). Still, we feel there is value in this exercise to the hydrology community at large such that we conclude here with teacher reflections on the inclusion of active learning and the overall course itself.

\subsection{Teacher reflections}

\subsubsection{On the active learning environment}

The size of the course (6 students) was intentionally kept low to help with logistical planning during this initial offering of the course Ecohydrology: A Mediterranean perspective. As such, managing the high-level of active learning (particularity in TLA \#3) was rather efficient and effective. We do feel that this course structure, however, can be scaled up to the about 20 students. For example, considering ILO \#3, students could be divided into several small groups to design and conduct different and/or complimentary experiments. The results of these different experiments could then be synthesized (either by the teachers or the students as an additional exercise) to build a broader sense of ecohydrology. To scale the course beyond about 20 students will most likely lead to logistic problems that can be common with any larger course. Such a large course size would also start to push the upper limit of what we would expect to see with regards to a cohort of students in a second-year Master's level course. Of course, this confidence in scaling up the course is only valid for a summer course or a course where students are dedicated full time. Different consideration would be needed with regard to recreating this course, for example, within the context of a standard schedule of courses like those on offer at many universities around the world.

The number of students considered here may also make the student feedback less reliable due to a small population size. While this is a potential shortcoming to this current study, the small course size, in our opinion, helped create a fair amount of candor between students and teachers. As such, we tend to lend credibility to the students' reflections while being aware of the potential for bias (e.g., Pathirana et al., 2012) with regards to evaluating education. Still, this would be improved with a more structured interview methodology to assess student opinions. Further, we have not assessed student learning in the course using any examination-based assessment (see the Supplement) due to the problems associate with such traditional assessment methods in problem-based learning environments (Lyon and Teutschbein, 2011). As such, we present our own selfreflection here with regards to student performance in this course relative to our collective experiences in other courses offering more traditional forms of learning. 
With regards to student involvement in the course, the level of active learning used in the course considered in this case study created more enthusiasm in the classroom than we typically associate with traditional learning environments. This potentially reflects the feeling of ownership of the education expressed by the students and, in our opinion, likely facilitates self-regulation of learning. From the teacher perspective, this generally higher level of enthusiasm also makes teaching more enjoyable in a general sense creating a feedback effect whereby the teachers can become more involved in the learning process. Further, by having students develop and design experiments it allowed the level of teacher-student discourse in the classroom to be elevated over more traditional learning environments thus placing teachers and students on a consistent level (i.e., everyone was a researcher in the class). This consistent level aided communication which we feel helped facilitate knowledge transfer since it fostered an environment where students were not afraid to ask questions and/or offer opinions. This selfreflection is consistent with the results from the study by Lyon and Teutschbein (2011) on the utility of problem-based learning in the classroom.

Counter to potential benefits, such an open environment might be uncomfortable for some students. Still, such an atmosphere from the teachers' perspective is rather stimulating and appropriate in a second-year Master's level course. To help alleviate some student apprehension, one could consider more hybrid approaches that couple both active learning and lecture-based approaches. As such, teachers could start with more traditional forms of teaching and slowly transfer and incorporate an active learning environment across the span of a course. With respect to this current case study course, we fully anticipate such hybridization will occur in future offerings. This should help lessen students' reflections regarding a "lack of structure" over time as we further develop and improve upon this course.

\subsubsection{On getting more "ecohydrological"}

Clearly, this course is in its infancy and will need further development to achieve the status of a fully vetted ecohydrology course. Being aware of this, we reflect here on some of the potential limitations of the current course with regards to ecohydrology education and identify possible pathways forward to achieve a more ecohydrological-centric course. In the first offering of this course, it tended to focus on the more physical aspects of ecohydrology both by design due to the backgrounds of the students and by being coupled with a hydrology Master's program. There was a limited amount of consideration given to other aspects (i.e., unique plant adaptations to limited water availability or differences in water use between native plants and irrigated crops) across the field, in part due to student direction, i.e., the students may have tended to choose activities with which they were somewhat familiar. Thus, the instructors need to consistently as- sess student progress to ensure that the intended material is covered in the course. In future offerings of the course, the instructors plan to include activities that intentionally incorporate more physiological ecohydrology aspects into the course such as consideration of rooting depth into model development or exploring stomata response controls on transpiration. It is envisioned that this will allow us to better leverage the uniqueness of the Navarino Environmental Observatory (NEO) by having students make detailed measurements on, for example, old-growth olive orchards in proximity to actively managed and landscaped coverages.

We highlight this realized shift of focus away from the "eco" in ecohydrology as a potential limitation of a pure active learning environment where instructor control may be sacrificed. As such, there might not be the opportunity to explore all the aspects of a given subject (particularly one as broad as ecohydrology) in detail. During the course, we became aware of this focus on the more physical aspects of ecohydrology. So, to help distinguish from the standard teaching of evapotranspiration offered in any general hydrology course, we broke script during TLA \#3 to put together a demonstration aimed at drawing students' attention to the impact of biological adaptation to evaporation at the Navarino Environmental Observatory. This (admittedly ad hoc) activity consisted of a small experiment to demonstrate the impact of plant type (broad leaf vs. needle leaf) on evaporation. The Mediterranean setting and focus of the course aided in demonstrating plant adaptations to limited water availability as there are clear differences in water use across plant type and water management. As such, by improvising on the course script, we were able to bring in more physiological aspects of ecohydrology. This eye to flexibility and adaptation is an important aspect to be aware of when designing trying to bring together active learning and ecohydrology education.

Another clear step forward to raise the level of ecohydrology considered in this type of course would be the involvement of local experts from the region. This would offer up more familiarity with local vegetation and ecology, thereby making it possible to address, for example, potential regional changes seen to date in the landscape and their connection with hydrology. For this specific course, we are planning to involve instructors and students from the nearby University of Peloponnese and the Messinia region in the next offering. Further, there are additional plans to cross-list the course in the Landscape Ecology Master's program at Stockholm University. This will likely accomplish two goals. First, it will allow us to involve instructors with specific knowledge in landscape ecology, which opens up new areas of expertise to this course. Second, it will create a more mixed class setting such that exchange and paired learning can take place between students from hydrology and ecology perspectives. 


\section{Concluding remarks}

We have intended this case study to help serve as a potential road map for designing and implementing ecohydrology courses with respect to existing hydrology programs. In our case study example, we target plant-water interactions within the realm of ecohydrology from a Mediterranean perspective. While this suited our needs, such focus is clearly not necessary as the general structure presented here could be adopted to any of the "spheres" within ecohydrology (McClain et al., 2012) or be developed to leverage off of any established or startup field sites. Independent of the details, any ecohydrology course will by nature likely tend towards cross-disciplinary and inter-disciplinary work that warrants the consideration of active learning approaches. From our case study, students identified the utility of such approaches over their more traditional, lecture-based counterparts for achieving course goals. With respect to "how active is active enough" we saw that there is potential for added value associated with additional "activeness" in our teaching. This is a positive take-home message for those of us faced with developing attractive and successful ecohydrology courses on potentially limited budgets and time.

\section{Supplementary material related to this article is available online at: http://www.hydrol-earth-syst-sci.net/ 17/269/2013/hess-17-269-2013-supplement.pdf.}

Acknowledgements. We are grateful to support and assistance to carry out the course Ecohydrology: A Mediterranean perspective. The work has (in part) been carried out within the framework of the Navarino Environmental Observatory (NEO), Messinia, Greece, a cooperation between Stockholm University, the Academy of Athens and TEMES S.A. NEO is dedicated to research and education on the climate and environment of the Mediterranean region. We thank Nikos Kalivitis for his immense help with planning and logistics. We also acknowledge support from the Stockholm University Academic Initiative to allow for exchanges and planning visits between Stockholm University and Cornell University. Lastly, we thank the students involved in the course for their effort and enthusiasm throughout and thoughtful comments by Christine Stumpp, Michael McClain, Steve Shaw, and an anonymous reviewer that have helped refine and improve the presentation of this work.

Edited by: C. Stumpp

\section{References}

Allen, R. G., Pereira, L. S., Raes, D., and Smith, M.: Crop evapotranspiration: Guidelines for computing crop requirements, Irrigation and Drainage Paper No. 56, FAO, Rome, Italy, 1998.
Arthington, A. H., Naiman, R. J., McClain, M. E., and Nilsson, C. Preserving the biodiversity and ecological services of rivers: new challenges and research opportunities, Freshwater Biol., 55, 116, doi:10.1111/j.1365-2427.2009.02340.x, 2010.

Berry, L.: Collaborative Learning: A Program for Improving the Retention of Minority Students, US, Virginia, 1991-00-00, ED384323, 1991.

Biggs J. and Tang C.: Teaching for quality learning at university, Open University Press/Mc Graw-Hill Education, 335 pp., 2007.

Bonwell, C. and Eison, J.: Active Learning: Creating Excitement in the Classroom, AEHE-ERIC Higher Education Report No. 1, Washington DC, Jossey-Bass, 1991.

d'Odorico, P., Laio, F., Porporato, A., Ridolfi, L., Rinaldo, A., and Rodriguez-Iturbe, I.,: Ecohydrology of terrestrial ecosystems, BioScience, 60, 898-907, doi:10.1525/bio.2010.60.11.6, 2010.

Drake, J. R.: A critical analysis of active learning and an alternative pedagogical framework for introductory information systems courses, Journal of Information Technology Education: Innovations in Practice, 11, 39-52, 2012.

Eagleson, P. S.: Climate, soil and vegetation. 1. Introduction to water balance dynamics, Water Resour. Res., 14, 705-712, 1978.

Hack, J. T. and Goodlett, J. C.: Geomorphology and forest ecology of a mountain region in the central Appalachians, United States Geological Survey, Professional Papers, 347 pp., 1960.

Hake, R.: Interactive-engagement vs. traditional methods: A sixthousand-student survey of mechanics test data for introductory physics courses, Am. J. Phys., 66, 64-74, 1998.

Hannah, D. M., Wood, P. J., and Sadler, J. P.: Ecohydrology and hydroecology: A "new paradigm"?, Hydrol. Process., 18, 3439 3445, 2004.

Hargreaves, G. H. and Samani, Z. A.: Estimating potential evapotranspiration, Technical Note, Transactions of the American Society of Agricultural Engineering, 108, 225-230, 1982.

Huba, M. E. and Freed, J. E.: Learner-centered Assessment on College Campuses: Shifting the Focus from Teaching to Learning, Allyn \& Bacon, Boston, MA, 2000.

King, E. G. and Caylor, K. K.: Ecohydrology in practice: strengths, conveniences, and opportunities, Ecohydrology, 4, 608-612, doi:10.1002/eco.248, 2011.

Kirschner, P. A., Sweller, J., and Clark, R. E.: Why minimal guidance during instruction does not work: An analysis of the failure of constructivist, discovery, problem-based, experiential, and inquiry-based teaching, Educ. Psychol., 41, 75-86, 2006.

Knight, R. D.: Five Easy Lessons: Strategies for Successful Physics Teaching, Addison Wesley, San Francisco, CA, 61 pp., 2004

Langbein, W. B.: Annual Runoff in the United States, US Geological Survey Circular 52, 14 pp., 1949.

Levia, D. F. and Quiring, S. M.: Assessment of Student Learning in a Hybrid PBL Capstone Seminar, J. Geogr. Higher Educ., 32, 217-231, 2008.

Lyon, S. W. and Teutschbein, C.: Problem-based learning and assessment in hydrology courses: Can non-traditional assessment better reflect intended learning outcomes?, Journal of Natural Resources and Life Sciences Education, 40, 199-205, doi:10.4195/jnrlse.2011.0016g, 2011.

McClain, M. E., Chícharo, L., Fohrer, N., Gaviño Novillo, M., Windhorst, W., and Zalewski, M.: Training hydrologists to be ecohydrologists and play a leading role in environmental problem solving, Hydrol. Earth Syst. Sci., 16, 1685-1696, 
doi:10.5194/hess-16-1685-2012, 2012.

Mayer, R. E.: Should there be a three-strikes rule against pure discovery learning?, Am. Psychol., 59, 14-19, 2004

Monteith, J. L.: Evaporation and surface temperature, Q. J. Roy. Meteorol. Soc., 107, 1-27, 1981.

Neilsen, T. B. Strong, W. J., Anderson, B. E., Gee, K. L., Sommerfeldt, S. D., and Leishman, T. W.: Creating an active-learning environment in an introductory acoustics course, J. Acoust. Soc. Am., 131, 2500-2509, 2012

Pathirana, A., Koster, J. H., de Jong, E., and Uhlenbrook, S.: On teaching styles of water educators and the impact of didactic training, Hydrol. Earth Syst. Sci., 16, 3677-3688, doi:10.5194/hess-16-3677-2012, 2012.

Penman, H. L.: Natural evaporation from open water, bare soil and grass, Proc. R. Soc. London, A193, 120-145, 1948.

Penman, H. L.: Vegetation and Hydrology, Commonwealth, Agricultural Bureaux: Farnham Royal, 1963.

Prince, M.: Does Active Learning Work? A Review of the Research, J. Eng. Educ., 9, 223-231, 2004.

Shaw, S. B. and Walter, M. T.: Using comparative analysis to teach about the nature of nonstationarity in future flood predictions, Hydrol. Earth Syst. Sci., 16, 1269-1279, doi:10.5194/hess-161269-2012, 2012.
Spronken-Smith, R.: Implementing a problem-based learning approach to teaching research methods in geography, J. Geogr. Higher Educ., 29, 203-221, 2005.

Thornthwaite, C. W. and Holzman, B.: The determination of evaporation from land and water surfaces, Mon. Weather Rev., 67, 4-11, 1939.

Turc, L.: The water balance of soils, relation between precipitation evaporation and flow, Ann. Agronomiques, 5, 491-569, 1954.

van Griensven, A., Meixner, T., Grunwald, S., Bishop, T., Diluzio, A., and Srinivasan, R.: A global sensitivity analysis tool for the parameters of multi-variable catchment models, J. Hydrol., 324, 10-23, doi:10.1016/j.jhydrol.2005.09.008, 2006.

Wagener, T., Weiler, M., McGlynn, B., Gooseff, M., Meixner, T., Marshall, L., McGuire, K., and McHale, M.: Taking the pulse of hydrology education, Hydrol. Process., 21, 1789-1792, 2007.

Wilcox, B. P.: Transformative ecosystem change and ecohydrology: ushering in a new era for watershed management, Ecohydrology, 3, 126-130, doi:10.1002/eco.104, 2010. 